\title{
Variation in incidence trends of malignant pleural mesothelioma in Europe
}

To the Editor:

We read with interest the article by Ji et al. [1] regarding the epidemiology of malignant pleural mesothelioma (MPM) in Sweden and familial clustering. The data in the study show the incidence of MPM in Sweden peaked in 2000 and has sharply declined since 2005. Data from other countries suggest a more delayed peak [2-4]. The highest annual incidence of MPM in the world has been reported to occur in the UK and Australia [5]. The incidence of MPM was predicted to peak in UK between 2011 and 2015; this was based on the known associated high latency period and the ban in using asbestos-containing products [6]. This variability in incidence trends across Europe can be explained by the different dates of asbestos bans in Europe, but Ireland migration trends also potentially play a role. Data from our institute indicates that the incidence of malignant mesothelioma has been increasing over the last decade (20 new cases diagnosed in 2002-2008 versus 26 cases in 2009-2013, an increase of 30\% (95\% CI 11.9-54.2\%)). These findings are consistent with the statistics from the National Cancer Registry Ireland (figure 1) [7].

FIGURE 1 Incidence of malignant pleural mesothelioma cases in Ireland in the period 1994-2014. Data from the National Cancer Registry Ireland [7].

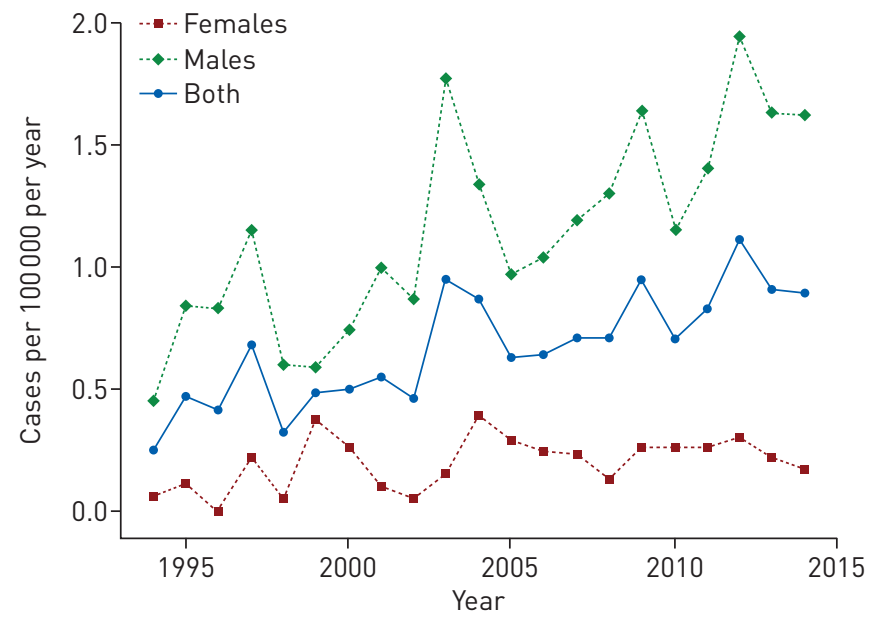

The return to Ireland of retirement-age lower socio-economic classes who have previously worked in asbestos-related industries in the UK seems to be one of the factors contributing to this peak in incidence. The number of Irish returning migrants has nearly tripled in the period 2001-2011 compared to 19811990, and just over a half came from the UK [8]. In addition, this has also coincided with improved diagnostic and management strategies, including medical thoracoscopy, which in many institutions fall under the purview of pulmonologists. With the demographic changes associated with free movement across Europe, careful evaluation of the epidemiology of a rare disease such as MPM should be taken beyond simply extrapolating data regarding asbestos imports and ban dates.

@ERSpublications

The incidence of malignant pleural mesothelioma is rising in some European countries; migration trends play a role http://ow.ly/YPRr30hAd3T

Cite this article as: Ahmed M, Flannery A, Mujammil I, et al. Variation in incidence trends of malignant pleural mesothelioma in Europe. Eur Respir J 2018; 51: 1702384 [https://doi.org/10.1183/13993003.023842017]. 
Mohammed Ahmed $^{1}$, Antoinette Flannery ${ }^{1}$, Irfan Mujammil ${ }^{2}$ and David Breen ${ }^{1}$

${ }^{1}$ Interventional Respiratory Unit, Galway University Hospitals, Galway, Ireland. ${ }^{2}$ Dept of Respiratory Medicine, Royal Preston Hospital, Fulwood, Preston, UK.

Correspondence: Mohammed Ahmed, Interventional Respiratory Unit, Galway University Hospitals, Galway, Ireland. E-mail: Jamaleldeen@gmail.com

Received: Nov 182017 | Accepted: Nov 232017

Conflict of interest: None declared.

\section{References}

1 Ji J, Sundquist J, Sundquist K. Incidence and familial risk of pleural mesothelioma in Sweden: a national cohort study. Eur Respir J 2016; 48: 873-879.

2 Neumann V, Löseke S, Nowak D, et al. Malignant pleural mesothelioma: incidence, etiology, diagnosis, treatment, and occupational health. Dtsch Arzteblatt Int 2013; 110: 319-326.

3 Tomasson K, Gudmundsson G, Briem H, et al. Malignant mesothelioma incidence by nation-wide cancer registry: a population-based study. J Occup Med Toxicol Lond Engl 2016; 11: 37.

4 Vangelova K, Dimitrova I. Asbestos exposure and mesothelioma incidence and mortality in Bulgaria. Rev Environ Health 2016; 31: 203-209.

5 Robinson BM. Malignant pleural mesothelioma: an epidemiological perspective. Ann Cardiothorac Surg 2012; 1: 491-496.

6 Hodgson JT, McElvenny DM, Darnton AJ, et al. The expected burden of mesothelioma mortality in Great Britain from 2002 to 2050. Br J Cancer 2005; 92: 587-593.

7 Incidence statistics. National Cancer Registry Ireland. www.ncri.ie/data/incidence-statistics Date last accessed: October 20, 2017.

8 Census 2011 Profile 6 Migration and Diversity. A profile of diversity in Ireland. Central Statistics Office. www.cso. ie/en/census/census2011reports/census2011profile6migrationanddiversity-aprofileofdiversityinireland/ Date last accessed: October 20, 2017. 